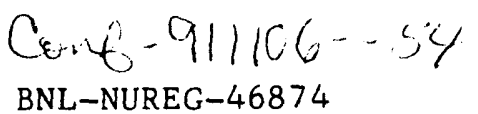

\title{
THE EFFECT OF PLANT AGING ON EQUIPMENT QUALIFICATION AND HUMAN PERFORMANCE ISSUES RELATED TO LICENSE RENEWAL*
}

\author{
W. E. Gunther and J. C. Higgins \\ Brookhaven National Lab \\ S. K. Aggarwal \\ U.S. Nuclear Regulatory Commission
}

BNL-NUREG - -46874

\begin{abstract}
The aging of nuclear power plants is one of the most important issues facing the nuclear industry worldwide. Aging encompasses all forms of degradation to nuclear power plant components, systems, and structures that result from exposure to environmental conditions or from operational stresses. Both the degradation from aging and actions taken to address the aging, such as increased maintenance and testing, can significantly impact human performance in the plant. Research into the causes and effects of aging as obtained through the assessment of operating experience and testing have raised questions regarding the adequacy of existing industry standards for addressing the concerns raised by this research. This paper discusses these issues, with particular emphasis in the area of equipment qualification and human performance.
\end{abstract}

\section{INTRODUCTION}

The U.S. NRC's hardware oriented engineering research program for plant aging and degradation monitoring has evaluated the susceptibility to aging of systems, structures, and components (SSCs) important to the safe operation of nuclear power plants (NPPs). The principal goals of the program, known as the Nuclear Plant Aging Research Program (NPAR), are to understand the effects of age-related degradation in NPPs and to manage them effectively. Results have been achieved in the area of electrical, control, and instrumentation (ECI) components encompassed by IEEE standards. Through the NRC's NPAR Program, degradation mechanisms and aging management techniques have been or are being evaluated for bistables, switches, transmitters, inverters, I\&C modules, cable penetrations, and isolation devices. In addition, the $\mathrm{ECl}$ components associated with systems such as the Emergency Diesel Generators, Control Rod Drive Systems, and Emergency Core Cooling Systems have been addressed for their aging significance. An evaluation of the operating experience of these components and systems, coupled with a determination of the materials of construction, operating and environmental stresses, and failure modes, causes, and effects have provided the NRC with the technical basis required to assure the continued safe operation of present reactors through the license renewal period.

An understanding of the aging process has been achieved in the NPAR Program. Aging is the cumulative degradation to an SSC from operational and environmental mechanisms such as cycling, transients, vibration, testing, temperature, and humidity These types of stresses have resulted in the degradation of certain subcomponents such as electrolytic capacitors, fuses, or power semiconductors which can effect the operation of various ECI equipment. Similarly, aging degradation associated with the mechanical properties of elastomers, connectors, and fuse holders have also resulted in ECI failures.

To a large degree, mitigation of this degradation is accomplished through a comprehensive maintenance program which incorporates predictive and condition monitoring techniques. Some questions remain, however, particularly related to the industry's need to factor agingrelated data into equipment qualification programs and staffing practices. The latter are associated with the additional maintenance and testing often required to manage aging.

\section{Discussion}

\section{Equipment Qualification}

The satisfactory performance of safety related or $1 \mathrm{E}$ electrical equipment uncier accident conditions throughout a plant's operating life has been the goal of equipment qualification standards and regulation. For the most part, however, emphasis has been placed on equipment located in harsh environments. Regulation 10 CFR 50.49

* This work done under the auspices of the U.S. Regulatory Commission.

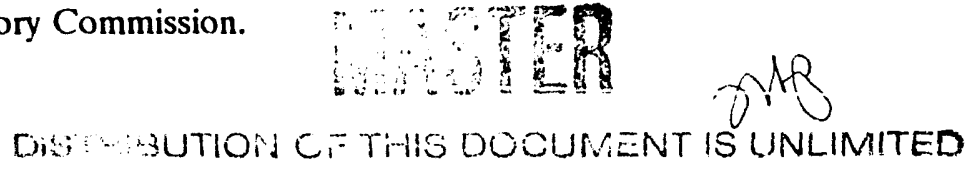


specifically states that the "environmental qualification of electrical equipment important to safety located in a mild environment are not included within the scope of this section". Based on the NPAR research, this approach may not be adequate to assure continued safe operation during the license renewal period. For example, power conditioning equipment such as battery chargers and inverters are the sources of power for the instrumentation buses, namely the vital ac bus (typically $120 \mathrm{Vac}$ ) and the essential dc bus (typically $125 \mathrm{Vdc}$ ). A high reliability for these components is important to assure that instrumentation and controls needed for the safe operation of the plant are available. An assessment of the operating experience, materials of construction, and application of this equipment revealed that a large percentage of failures are due to hardware degradation. NUREG/CR-4564 [1] reported that components such as capacitors, thyristors, and fuses are susceptible to aging and that their failure directly resulted in an outage of the inverter. In many cases, this also resulted in a plant transient or scram.

Further study, including testing of a naturally aged inverter from the decommissioned Shippingport facility and completion of a comprehensive survey of U.S. utilities, revealed that means exist for detecting and mitigating the effects of aging on inverters. In addition to certain design improvements, methods of maintenance, inspection, and testing have been identified for use in managing the aging of inverters in nuclear power planits. Recommendations from NUREG/CR-5051 [2] in this area include:

1. Since overheating is an important cause of stress, it is prudent to periodically monitor the internal cabinet temperature.

2. Cleaning can also minimize the risk of overheating; wiping thyristor heat sinks and ventilation flow paths improves the heat transfer away from temperature sensitive components.

3. Capacity testing is recommended especially for standby inverters. This verifies that the inverter can supply design loads, and permits inspection monitoring techniques to be applied at rated load.

Similar types of recommendations have been reported for circuit breakers, relays, batteries, and other ECI equipment located in mild environments. Often these recommendations exceed the periodic sub-component replacement requirements typically resulting from environmental qualification testing and analysis. To effectively manage the aging of this equipment requires extending the normal maintenance and testing program. This philosophy applies to operation of the plant over its entire life, including the license renewal term.

\section{Human Performance Issues Related to Plant Aging and License Renewal}

\subsection{Impact of Aging on Human Performance}

Both the age-related degradation of equipment and the resultant activities to mitigate such aging can have significant effects on human performance. Without effective programs to combat age-related degradation, there will be increased operator activities to monitor equipment, increased corrective maintenance activities as equipment fails, increased general cleanup and housekeeping due to added leakage and maintenance, and additional operator burden during plant transients due to the equipment degradation and failures. Most of the aging facilities however, are in the midst of establishing programs to address and mitigate this age-related degradation. But these very programs are often quite demanding on the existing plant staff, both in the short term to complete the program, and then in the longer term to implement the developed solutions to the aging phenomena.

Some specific examples will be discussed here. The aging evaluations and analyses themselves can be labor intensive both on the people performing the analyses and on other plant personnel needed to provide data on failures, maintenance, and test results to the analysts (e.g., Yankee Rowe Pressure Vessel). Inspection and monitoring programs for aging equipment can potentially be labor intensive in the specification, procurement and installation of monitoring equipment, the development of procedures, the collection of data, and the evaluation of the data. This also creates more information for operators to be cognizant of and to evaluate as they operate the plant. An example of this is the recommended monthly inspection of reactor trip breakers [3], and improved CCW system inspection activities [4].

A common mitigative action for aging is added testing to verify continued operability. Examples include, signature testing of MOVs [5], and Time Domain Reflective (TDR) Testing of Cables [6]. These actions require procedures to be written, tests be performed and results evaluated. During the performance of testing, equipment may be temporarily unavailable, causing operators to enter Technical Specification Action Statements and giving the operators fewer options in transient situations. Another mitigative action is increased maintenance. This also requires procedures be written, maintenance be performed and post-maintenance testing completed. An example here is maintenance on air compressor filters in instrument air systems [7]. While components are undergoing maintenance (either preventive or corrective) they are again unavailable to the 
opera.ors - adding to their burden in tracking plant status and in responding to events.

Another strategy is selective equipment replacement. In addition to the already noted requirements for specifications, procurement, procedures, installation, and testing, we now also must retrain the operating staff to operate the new equipment. Some examples of recommended modifications to mitigate aging are: counters to reactor trip breakers to monitor number of cycles to determine maintenance cycles [3], and the addition of fans to inverter enclosures to prolong life [2]. Capacitors of inverters were determined to need periodic replacement to avoid failure [2]. Another good example involving both modification and replacement is in the control room and I\&C area, where decades-old analog equipment is being replaced by digital equipment. Computer - generated displays and monitors are also being added. This creates a hybrid control room with various combinations of new and old technology. This raises issues of $I \& C$ testing and maintenance and control room operator training and performance. It is an area of current concern to NRC, and guidance for equipment designs in this area does not currently exist for nuclear power plants. Some of these changes are to improve the control room design, but others are due to unavailability of replacement/spare parts for the older equipment. This new equipment must be integrated into the operational scheme of the control room, and as a result many questions should be addressed; such as: How should the equipment be selected? What are the criteria for the advanced human-systems interface? How will operator's tasks change? Will the operators overall role change (e.g. more automated systems)? What is the impact on training? How should equipment be phased in? Should the NRC be involved in review of the equipment to be changed out? Poor integration of the new equipment will result in poor operator performance.

Thus, we can see that both plant aging and programs initiated to combat age-related degradation can significantly impact human performance at NPPs.

\subsection{Workforce Effects}

As NPPs age there are several issues which impact the staff or workforce of the plant. As discussed in Section 3.2, there are clearly a multitude of potential new programs and activities possible to address aging issues. These programs could vary and result in increases in staff sizes and in reorganizations to address the areas of new emphasis (e.g., inspection and monitoring of aging equipment). Some engineering staffs have already been supplemented to perform the various aging studies and analyses. These changes in staff size and composition also affect the organization and management of the plant, which must respond to such major changes.

Additionally many plants have had a quite stable workforce in that people have spent large portions of their career at that plant. This appears to result in older plants with a somewhat older average age worker. These workers have certainly accumulated valuable knowledge and plant experience, however, as these plants approach or pass their original 40 years life span, the question of the physical age of the workers becomes one that should also be addressed. Is the overall average age of the NPP worker increasing significantly and, if so, what impacts does this have? Do you need a mix of junior and senior personnel, e.g., senior personnel for experience and stability, but junior personnel for flexibility, physical skills, and attentiveness? Do stress and fatigue (commonly present at NPPs) have to be addressed differently as workers age, particularly shift workers? Further, as modifications are made to the plant and retraining becomes necessary, those who have operated the old systems for many years may need special training emphasis, both due to the time spent with the original systems and because retraining of older persons has been shown to take longer $[8,9]$. Also, the types of new skills required by the workforce (e.g., computer literacy) may require considerable adaptation and retraining by many older individuals.

Thus, while plant aging has to date addressed equipment, we can see that workforce effects (such as increases in staff, reorganization, management changes, and aging of the staff) should not be ignored.

\subsection{Risk Perspective}

The various aging and human performance issues discussed above can have a notable effect on plant risk as analyzed and estimated using Probabilistic Risk Assessment/Human Risk Assessment (PRAMRA) techniques. One significant PRA effect is the potential decrease in equipment component reliability (or increase in failure rates) as they age. This has been addressed in many other studies (e.g., [10] and [11]) and will not be covered here. The additional effects on equipment availability and human performance, resulting from the changes noted above, are discussed here.

Many of the programs to address aging, described above, result in increases in plant testing, component maintenance, and equipment replacement. All of these have the potential to periodically remove equipment from service, making it unavailable for service should it be needed in an emergency. This increase in equipment unavailability will increase risk. 
The effects of aging on human performance may aiso create opportunities for new human errors not currently modeled in the PRA, or may change the existing errors already modeled. As an example of new errors, when equipment is replaced with new and different components or designs, this creates the possibility for errors which previously were not considered. One example would be in the control room, where there is a trend toward more CRT-based monitors, automated systems, and digital controls. These give the operator a very different perspective on plant status and change the way $C R$ errors need to be considered. Some pertinent issues are: higher cognitive workload for operators, loss of situation awareness, loss of vigilance, and actions on computer failure. This is further discussed in another BNL paper at this conference [12].

Regarding changes to existing types of errors, current PRAs contain pre-accident and during-accident human errors, both of which can be affected by age related issues. There may be more of these types of errors or changes in the error rates. In the pre-accident time regime of an aged plant, there is more operator interaction with equipment due to increases in testing and maintenance. As a result there are more opportunities for the operator to incorrectly restore the tested (or maintained) equipment to an operable status upon completion of the work. These are called "failure to restore" errors.

The during-accident errors are generally further categorized as procedurally-related errors and recovery errors, although the distinction is not always clear cut. Some of the age-related activities are resulting in further procedural guidance for the operators during transient activities which would compensate for added equipment failures caused by aging. This increase in procedural guidance naturally creates the opportunity for more operator errors, of the type already modeled in the PRA.

Recovery type errors result from the PRA practice of giving operators credit for being able, in certain situations, of recovering or repairing initially-failed equipment. These are modeled in the PRA as a "failure to recover" with a certain failure probability (e.g., 0.1 ). This means that in $10 \%$ of the cases the operator will not recover the failed component but in $90 \%$ of the cases the operator will recover. Considering an aged plant, equipment may be more likely to fail catastrophically. If this is the case, the ability to recover or repair the component will be severely limited. Additionally, recovery of failed components during an accident situation will entail moderate to high stress and may need to be performed out in the plant with resultant poor environment (high heat, humidity or radiation levels), poor equipment accessibility (climbing or stretching), or large manual forces required (e.g., large sized manual valve override, increased rust or wear, etc.). If these recovery actions are to be performed by an older workforce, their overall likelihood of success should decrease.

Thus, we can see that there are a number of situations where new error possibilities are created, and where failure probabilities can increase, resulting in an increase in the bottomline risk.

\section{Conclusion}

The results of research completed through the U.S. NRC's NPAR Program demonstrates that the aging process is significant for ECI devices, even those located in mild environments. To maintain the high reliabilities expected of these devices, nuclear power plant staffs must expand their existing environmental qualification programs to address the aging that has occurred and which will be experienced during the license renewal term. This may require additional maintenance, testing, and monitoring.

There are many human performance issues that are raised both by plant aging and by the programs being proposed to address plant aging. There are also changes in staff composition for a number of reasons as plant age. The impact on human performance, both individually and collectively, of proposed solutions to aging should be carefully considered and addressed. Changes in staff composition can be both part of the problem and part of the solution and also should be carefully examined.

\section{REFERENCES}

[1] W. E. Gunther, et al, "Operating Experience and Aging-Seismic Assessment of Battery Chargers and Inverters," NLIREG/CR-4564.

[2] W. E. Gunther, et al, "Detecting and Mitigating Battery Charger and Inverter Aging," NUREG/CR5051.

[3] M. Subudhi, et al, "Age-Related Degradation of Westinghouse 480-Volt Circuit Breakers; Vol. 2, Mechanical Cycling of a DS-416 Breaker. Test Results," NUREG/CR-5280.

[4] R. Lofaro, et al, NUREG/CR-5693, (DRAFT) "Aging Assessment of CCW System in BWRs, Phase II," Draft, March 1991.

[5] W. L. Greenstreet, et al, "Aging and Service Wear of Electric Motor-Operated Valves Used in Engineered Safety-Feature Systems of Nuclear Power Plants: Aging Assessment and Monitoring Method Evaluations," NUREG/CR-4234, Vol. 2. 
[6] G. J. Toman, "Inspection, Surveillance, and Monitoring of Electrical Equipment Inside Containment of Nuclear Power Plants-With Applications to Electrical Cables," NUREG/CR-4257.

[7] M. Villaran, "Aging Assessment of Instrument Air Systems in Nuclear Power Plants," NUREG/CR-5419.

[8] J. Korteling, "Effects of Skill Integration and Perceptual Competition on Age-Related Differences in Dual Task Performance," Human Factors Journal, Vol. 33, No. 1, February 1991.

[9] W. Rogers, and A. Fisk, "Age-Related Differences in the Maintenance and Modification of Automatic Processes: Arithmetic Stroop Interference," Human Factors Journal, Vol. 33, No. 1, February 1991.

[10] P. Samanta, et al, "Degradation Modeling with Application to Aging and Maintenance Effectiveness Evaluations," NUREG/CR-5612, January 1991.

[11] J. Higgins, et al, "Operating Experience and Aging Assessment of CCW Systems in PWRs," NUREG/CR5052.

[12] J. O'Hara, and R. E. Hall, "Advanced Control Rooms and Crew Performance Issues: Implications for Human Reliability," IEEE Nuclear Science Symposium, November 1991.

This report was prepared as an account of work sponsored by an agency of the United States Government. Neither the United States Government nor any agency thereof, nor any of their employees, makes any warranty, express or impliec, or assumes any legal liability or responsibility for the accuracy, completeness, or usefulness of any information, apparatus, product, or process disclosed, or represents that its use would not infringe privately owned rights. Reference herein to any specific commercial product, process, or service by trade name, trademark, manufacturer, or otherwise does not necessarily constitute or imply its endorsement, recommendation, or favoring by the United States Government or any agency thereof. The views and opinions of authors expressed herein do not necessarily state or reflect those of the United States Government or any agency thereof. 


$$
\begin{aligned}
& \text { DATE } \\
& \text { FILMED } \\
& 2121192
\end{aligned}
$$


